\title{
Correspondance
}

\section{Physician, regulate thyself!}

W e could not agree more with a $C M A 7$ editorial $^{1}$ that suggests confidence in physicians is at the core of what we do. We also agree that strong licensing and regulatory bodies are needed.

Long before the Shipman case came to light in the United Kingdom, medical regulatory authorities in Canada began making significant progress toward transparency and increased public accountability. There are now more public representatives on the councils of the regulatory authorities, and most disciplinary hearings are open to the public and the media.

Furthermore, the medical regulatory authorities recognize that a physician's performance may decline over time, and that the quality and safety of any individual physician's practice need regular review. Thus, the top priority for the Federation of Medical Regulatory Authorities of Canada is revalidation of licensure.

Medical regulatory authorities around the world are examining the recommendations in the fifth report of the Shipman Inquiry ${ }^{2}$ with a view to doing everything possible to prevent a similar occurrence in their own jurisdictions. Although our organizations must learn from this sad and appalling case, it is an extreme example of failure in a multicomponent system and should not be viewed as representative of the system as a whole.

\section{Bob Burns}

At the time of writing:

President

Federation of Medical Regulatory

Authorities of Canada

Ottawa, Ont.

\section{References}

1. Can physicians regulate themselves? [editorial]. CMA7 2005;172(6):717.

2. Smith J. Safeguarding patients: lessons from the past - proposals for the future. Command Paper Cm 6394. London (UK): The Shipman Inquiry; 2004 Dec 9. Available: www.the-shipman-inquiry .org.uk/fifthreport.asp (accessed 2005 Jun 25).

DOI:10.1503/cmaj.1050159
$\mathrm{T}$ he $C M A 7$ editorial on physician self-regulation ${ }^{1}$ is an opportunity for us to scrutinize our own systems in an international context.

The editorial is correct in emphasizing that self-regulation is but one ingredient in what should be a closely integrated system of quality management. ${ }^{2}$ However, it would be incorrect to conclude that clinical governance in the United Kingdom has been a failure.

Dame Janet Smith concentrated on the role of the General Medical Council (GMC) in her fifth report on the Shipman Inquiry; ${ }^{3}$ as a result, implementation of the GMC's revalidation scheme, due in April 2005, was postponed. ${ }^{4}$ She was concerned about the balance of professional and public interests, specifically that revalidation as planned would not achieve an adequate evaluation of fitness to practise. This is now likely to become a responsibility of the National Health Service, tied to appraisal. ${ }^{5}$

The UK Department of Health has implemented sweeping reforms in governance, finalized in February 2005 . $^{6}$ Governance is now based on modern management and human resources theory and empirical psychological research. This and the GMC reforms were part of a radical response to past crises and emphasize prevention rather than blame. The success of these changes must ultimately be measured in improvements in the quality of care.

In Canada the move toward appraisal in several provinces is welcome, as is a national perspective through the Federation of Medical Regulatory Authorities of Canada.?

The Shipman case should be seen in the context of a series of tragedies and an evolving understanding of how things go wrong in health care. In the past we have handled these events poorly, and reactively rather than proactively. We should look eagerly at lessons learned in other jurisdictions to see how they might be applied in our own system.

Despite the admonitions in Dame Janet's report, physicians, patients and society ultimately have the same goals, and concentrating on what we have in common is most likely to succeed in the long run. This is the basis of what has come to be known as "professionalism."

\author{
Michael Goodyear \\ Faculty of Medicine \\ Dalhousie University \\ Halifax, NS
}

\section{References}

1. Can physicians regulate themselves? [editorial] CMA7 2005;172(6):717.

2. National Steering Committee on Patient Safety. Building a safer system: a national integrated strategy for improving patient safety in Canadian bealth care. Ottawa: Health Canada; 2002. Available: http://rcpsc.medical.org/publications/building_a _safer_system_e.pdf (accessed 2005 Jul 4).

3. Smith J. Safeguarding patients: lessons from the past - proposals for the future. Command Paper Cm 6394. London (UK): The Shipman Inquiry; 2004 Dec 9. Available: www.the-shipman-inquiry .org.uk/fifthreport.asp (accessed $2005 \mathrm{Jul} 4$ ).

4. GMC reforms \& clinical governance. Postponement of licensing and revalidation [online]. London (UK): General Medical Council; [date unknown]. Available: www.gmc-uk.org/cg/index htm (accessed $2005 \mathrm{Jul} 4)$.

5. Learning and personal development: appraisals [online]. London (UK): UK Department of Health; 2005. Available: www.dh.gov.uk/PolicyAnd Guidance/HumanResourcesAndTraining/Learning AndPersonalDevelopment/Appraisals/fs/en (accessed $2005 \mathrm{Jul} 4$ ).

6. Maintaining bigh professional standards in the modern NHS [online]. London (UK): Department of Health; 2005 Feb. Available: www.dh.gov.uk/asset Root/04/10/33/44/04103344.pdf (accessed 2005 Mar 29).

7. Purpose, objects and guiding principles [online] Ottawa: Federation of Medical Regulatory Authorities of Canada. Available: www.fmrac.ca/index .cfm? fuseaction=content $\& \mathrm{ID}=32 \&$ mainID $=16(\mathrm{ac}-$ cessed 2005 Jul 6).

8. Report to Health Canada. Professionalism Program. Changes in bealth care: charting a new course. Ottawa: Royal College of Physicians and Surgeons of Canada; 2003 Sep 12. Available: http://rcpsc medical.org/publications/index.php (accessed 2005 Jun 28). Choose document by title.

DOI:10.1503/cmaj.1050086

\section{Patients beware}

A reported by Laura Eggertson, ${ }^{1}$ - some health care professionals foresee the need to ameliorate the drug approval mechanism in the United States and Canada. From the patient's point of view, there is also a need for a more comprehensive and transparent approach within the medical community to informing patients about the potential risks of newly released drugs.

The evidence used in Health 
Canada's drug approval process may be based on clinical trials or "real world" trials (or both), ${ }^{2}$ but under the current policy, patients receiving a prescription for a new drug will be unaware of the full scope of the evidence. If it consists solely of data from randomized clinical trials, then patients ought to be informed that there may be limitations in detecting unmeasured or rare adverse outcomes that might appear later in a real world setting, in observational studies or in additional clinical trials.

The proposal by Eike-Henner Kluge that newly released drugs be given conditional licences until the outcomes of phase IV studies are known ${ }^{1}$ would ensure that health care professionals inform patients that the prescribed drug is still under review by Health Canada. Patients who decide to take the new drug (after being informed of the benefit-risk balance, the alternative options and their effectiveness, costs and uncertainties) should then be monitored for adverse effects and any such adverse outcomes reported to appropriately designated authorities.

From an ethical point of view, there are similarities between patients who participate in randomized controlled studies and those who participate in real world trials, since in both types of studies, drug efficacy and safety are still under review. Therefore, it seems to me that the ethical guidelines currently applied for the first group should also be applied to consumers of medications prescribed under conditional licences. ${ }^{4}$

\section{Joseph Erban}

Member, Clinical Ethics Committee

Sir Mortimer B. Davis - Jewish General Hospital

Montréal, Que.

\section{References}

1. Eggertson L. Drug approval system questioned in US and Canada. CMA7 2005;172(3):317-8.

2. Laupacis A, Paterson JM, Mamdani M, Rostom A, Anderson GM. Gaps in the evaluation and monitoring of new pharmaceuticals: proposal for a different approach [editorial]. CMA7 2003;169(11):1167-70.

3. Juni P, Nartey L, Reichenbach S, Sterchi R, Dieppe PA, Egger M. Risk of cardiovascular events and rofecoxib: cumulative meta-analysis. Lancet 2004;364:2021-9.

4. Tri-Council policy statement. Ethical conduct for research involving humans. Ottawa: Medical Research Council of Canada, Natural Sciences and Engineer- ing Research Council of Canada, Social Sciences and Humanities research Council of Canada; 2003 Jun. Available: www.pre.ethics.gc.ca/english /pdf/TCPS June2003_E.pdf(accessed 2005 Jun 2).

The opinions expressed here are solely those of the author and do not represent the views of the Clinical Ethics Committee or the Sir Mortimer B. Davis Jewish General Hospital.

DOI:10.1503/cmaj.1050064

\section{Psychological aftermath of abortion}

W illiam Fisher and associates, ${ }^{1}$ in their article on women undergoing repeat induced abortion, state, "Evidence also does not indicate that women seeking repeat abortion are psychologically maladjusted."

Although this statement is not directly connected to the main study reported by Fisher and associates, we feel that it might mislead readers about psychological problems after abortion. Consider the following material from the literature:

- A recent study sponsored by the College of Physicians and Surgeons of Ontario compared 41000 women who had undergone induced abortion with a similar number who had not undergone abortion ${ }^{2}$ and found 5 times more hospital admissions for psychiatric problems among the women who had had abortions. This short-term study was conducted at 3 months after the abortions and did not address long-term effects or problems among women who were not admitted to hospital after abortion.

- In a study reported in this journal in 2003, Reardon and colleagues ${ }^{3}$ found a significantly higher risk of psychiatric admissions among lower-income women who had undergone induced abortions.

- In the course of our own research, we have found numerous reports of significant problems among women who have had an abortion. For example, a study from Finland ${ }^{4}$ showed a 6-fold greater incidence of suicide among women who had had an induced abortion than among women with normal pregnancies. In fact, many of over 70 scientific articles that we reviewed for a recent publication $^{5}$ reported various degrees of psychological problems after abortion.

- Increasing numbers of postabortion counselling services are being developed in North America and around the world. The largest in the United States is Project Rachel, which has many chapters, including several in Canada. ${ }^{6}$ Thousands of women are being helped by these services, sometimes long after the abortion, but there are undoubtedly many more who do not go for help.

- The Healing Choice postabortion counselling service, which is prochoice, estimates that at least $10 \%$ of women who have undergone an abortion need counselling for psychological problems associated with the procedure. ${ }^{7}$

On the basis of this evidence we can conclude that many women suffer problems after abortion. Given that follow-up after abortions is often lacking or short-term only, further research is needed in this area. Even if just 10\% of women who have had an abortion are experiencing these problems, this represents a substantial public health issue, considering that each year more than 100000 abortions are performed in Canada. ${ }^{8}$

\section{L.L. deVeber}

Professor Emeritus

University of Western Ontario

London, Ont.

\section{Ian Gentles}

Professor of History

York University

Toronto, Ont.

\section{References}

1. Fisher WA, Singh SS, Shuper PA, Carey M, Otchet F, MacLean-Brine D, et al. Characteristics of women undergoing repeat induced abortion. CMA7 2005;172(5):637-41.

2. Ostbye T, Wenghofer EF, Woodward CA, Gold G, Craighead J. Health services utilization after induced abortions in Ontario: a comparison between community clinics and hospitals. $\mathrm{Am} \mathcal{F}$ Med Qual 2001;16(3):99-106.

3. Reardon DC, Cougle JR, Rue VM, Shuping MW, Coleman PK, Ney PG. Psychiatric admissions of low-income women following abortion and childbirth. CMA7 2003;168(10):1253-6.

4. Gissler M, Hemminki E, Lonnquist J. Suicides after pregnancy in Finland, 1987-94: register linkage study. BM7 1996;313(7070):1431-4.

5. Ring-Cassidy E, Gentles I. Women's bealth after 